\title{
Nalbuphine versus Midazolam as an Adjuvant to Intrathecal Bupivacaine for Postoperative Analgesia in Patients Undergoing Cesarean Section
}

This article was published in the following Dove Press journal:

Journal of Pain Research

\section{Olfat Abdelmoniem Ibrahem Amin (D) \\ Mohamed Abdel-moniem Ibrahem (iD) ${ }^{2}$ \\ Dina Abdelhameed Elsadek Salem (ID) \\ 'Anesthesia and Surgical Intensive Care Department, Faculty of Medicine, Zagazig University, Alsharkia, Egypt; ${ }^{2}$ Obstetrics and Gynecology Department, Faculty of Medicine, Zagazig University, Alsharkia, Egypt}

Correspondence: Olfat Abdelmoniem Ibrahem Amin

Anesthesia and Surgical Intensive Care Department,Faculty of Medicine, Zagazig University, Alsharkia, Egypt

Tel +201004528999

Email olfath99@yahoo.com
Background and Purpose: Adding adjuvants to intrathecal hyperbaric bupivacaine provides long analgesic duration with less adverse effects. The aim of this study was to compare intrathecal nalbuphine versus midazolam in patients undergoing cesarean section.

Clinical Trial ID: NCT03918187.

Patients and Methods: This was a prospective randomized controlled study conducted on 90 females undergoing cesarean section under spinal anesthesia who were randomly allocated to three equal groups of 30 patients each: group $\mathrm{C}$ received hyperbaric bupivacaine $12.5 \mathrm{mg}$ plus $0.5 \mathrm{~mL}$ saline, group $\mathrm{N}$ received hyperbaric bupivacaine $12.5 \mathrm{mg}$ plus $1 \mathrm{mg}$ nalbuphine, group $\mathrm{M}$ received hyperbaric bupivacaine $12.5 \mathrm{mg}$ plus $2.5 \mathrm{mg}$ midazolam. The onset and duration of sensory and motor block, effective analgesic time, analgesic requirements, adverse effects, sedation, and Apgar scores were recorded.

Results: There was significant rapid onset of sensory and motor block (1.95 \pm .44 and 3.50 $\pm 0.43 \mathrm{~min}$ ) with slower regression of sensory block and time to bromage I (211.6 \pm 13.2 and $219.8 \pm 20.2 \mathrm{~min})$ in group $\mathrm{N}$ compared to groups $\mathrm{M}, \mathrm{C}(\mathrm{p}<0.001)$, with statistically significant rapid onset and long duration of both blocks in group $\mathrm{M}$ compared to $\mathrm{C}(\mathrm{p}<0.001)$. The effective analgesic time was significantly prolonged in group $\mathrm{N}(263.7$ $\pm 16.3)$ compared to groups $\mathrm{M}$ and $\mathrm{C}(224.2 \pm 18.6,185.5 \pm 17.45)$, respectively, $(\mathrm{p}<0.001)$ and prolonged in group $\mathrm{M}$ compared to $\mathrm{C}(\mathrm{p}<0.001)$, with increase in analgesic requirement in group $\mathrm{C}$ compared to groups $\mathrm{N}$ and $\mathrm{M}(\mathrm{p}<0.001)$ and no significant difference between groups $\mathrm{N}$ and $\mathrm{M}$. There was higher sedation score in groups $\mathrm{N}, \mathrm{M}(1.78 \pm 0.63,2.75 \pm 0.54)$, respectively, compared to group $\mathrm{C}(0.61 \pm 0.12)(\mathrm{p}<0.001)$ with lower Apgar score in group $\mathrm{M}(6.9 \pm 0.73)$ at one minute than in groups $\mathrm{N}, \mathrm{C}(7.1 \pm 0.91,7.7 \pm 0.84)(\mathrm{p}<0.001)$. There was no significant difference between groups regarding the adverse effects.

Conclusion: Adding $1 \mathrm{mg}$ nalbuphine to $12.5 \mathrm{mg}$ hyperbaric bupivacaine provided more effective postoperative analgesia than adding $2.5 \mathrm{mg}$ midazolam, with less non-significant adverse effects in midazolam group in patients undergoing elective cesarean section.

Keywords: cesarean section, spinal anesthesia, nalbuphine, midazolam, postoperative analgesia

\section{Introduction}

Analgesia is the most important factor for patients postoperatively. So it is important to provide good analgesia with less hazardous. Cesarean section is a painful operation which requires adequate postoperative analgesia. Adequate pain management is important to facilitate the functional recovery and enable patients to rehabilitate fast to return to their normal activities. ${ }^{1,2}$ 
Cesarean section is done under general anesthesia (GA) or regional anesthesia. Subarachnoid blockade is the preferred procedure. It avoids the depressant effect of GA on the neonate and also the risk of aspiration, with better postoperative pain relief. However the most commonly local anesthetic used, hyperbaric bupivacaine, has a limited effect which lasts for 1.5-2 hours. Its onset is slow with short duration of postoperative analgesia. ${ }^{3,4}$

Adjuvant drugs added to bupivacaine intrathecally improve the duration and quality of the blockade and prolong the postoperative analgesia. Various adjuvants are being used such as alpha ${ }_{2}$ agonists, neostigmine, opiates, ketamine etc, yet no drug has been identified to specifically inhibit nociception without side effects. ${ }^{5,6}$

Nalbuphine is a synthetic opioid with mixed agonist antagonist effect. It binds to both mu- and kappa receptors; binding of nalbuphine to mu receptors competitively displace other mu-agonists from these receptors without any agonist activity. Therefore decreasing the side effects of mu agonist (nausea, vomiting, respiratory depression, urinary retention, pruritis, and prolonged sedation). ${ }^{7}$ While when binding to kappa receptors, nalbuphine has agonist effect (analgesic effect) through the kappa receptors distributed in the brain and spinal cord. ${ }^{1}$ There have been no documented studies of nalbuphine neurotoxicity. ${ }^{5-8}$

Bindra et $\mathrm{al}^{5}$ compared intrathecal nalbuphine $0.8 \mathrm{mg}$ versus intrathecal fentanyl 20 microgram in cesarean section, and Culebras et $\mathrm{al}^{9}$ compared different doses of nalbuphine intrathecally $(1.6,0.8,0.2 \mathrm{mg})$ with intrathecal morphine in cesarean section also, both studies concluded that intrathecal nalbuphine was effective as adjuvant to hyperbaric bupivacaine and prolonged the postoperative analgesia in cesarean section.

Benzodiazepines are used mainly for sedation, anxiolysis, and amnesia. Discovery of their receptors in spinal cord allows the use of midazolam intrathecally for analgesia. Several studies have shown that the addition of intrathecal midazolam potentiates the analgesic effect of intrathecal bupivacaine without significant side effects, or neurotoxicity. ${ }^{10,11}$ Dodawad et $\mathrm{al}^{10}$ found that adding intrathecal $2 \mathrm{mg}$ midazolam as adjuvant to hyperbaric bupivacaine in patients undergoing cesarean section provided longer and effective postoperative analgesia.

There are several studies that studied the effect of intrathecal nalbuphine and intrathecal midazolam, but to our knowledge, no study has done a comparison between them.
The aim of this study was to compare intrathecal nalbuphine versus intrathecal midazolam in patients undergoing cesarean section. Our primary outcomes were to compare the effective analgesic time and analgesic requirement. Secondary outcomes were to compare the characteristics of sensory and motor block, adverse effects, sedation score, and Apgar score.

\section{Patients and Methods}

This study was approved by Zagazig University Institutional Review Board (IRB: 5305 - 17 - 3 - 2019) and written informed consent was obtained from all subjects participating in the trial. The trial was conducted in accordance with the Declaration of Helsinki and registered prior to patients' enrollment at clinicaltrial.gov (NCT03918187 -7/April/2019). Actual study start date was 10 April 2019 and the primary actual completion date was 30 August 2019. Consort checklist was applied for enrollment and allocation of the patients (Figure 1). Female patients with ASA grade II aged 18-40 years who presented for elective cesarean section (either primigravida or multi) under spinal anesthesia were included in this prospective randomized controlled double blind study.

Patients with history of hypertension, diabetes, cardiac diseases, psychiatric disorder, coagulopathy, allergy to the study drugs and any contraindication for spinal anesthesia, failure of spinal block, presence of fetal distress were excluded from the study.

All patients fasted 8 hours preoperatively and ultrasound evaluation and/or electronic fetal monitoring for assessment of fetal wellbeing were done prior to surgery. Routine investigations were done before surgery and patients were familiarized with the Numeric Pain Rating Scale (NPRS) $)^{12}$ for measuring of pain postoperatively.

Standard monitors; electrocardiogram, automated noninvasive blood pressure and pulse oximetry were attached; baseline data were detected, monitoring was started and observed every 5 minutes after spinal injection up to 60 minutes then every 2 hours for 4 hours postoperatively. Hypotension was considered if blood pressure decreased $>$ $25 \%$ from baseline. It was treated by intravenous (IV) ephedrine $5 \mathrm{mg}$ incremental dose as required, and IV fluid. Bradycardia was considered if heart rate decreased $<50$ beat/minute. It was treated by IV atropine sulphate $0.6 \mathrm{mg}$.

After IV line was secured preload was started with $10 \mathrm{~mL} / \mathrm{kg}$ ringer lactate, IV $50 \mathrm{mg}$ ranitidine and $4 \mathrm{mg}$ ondansetron were given. Using a computer-generated 


\section{Enrolment}

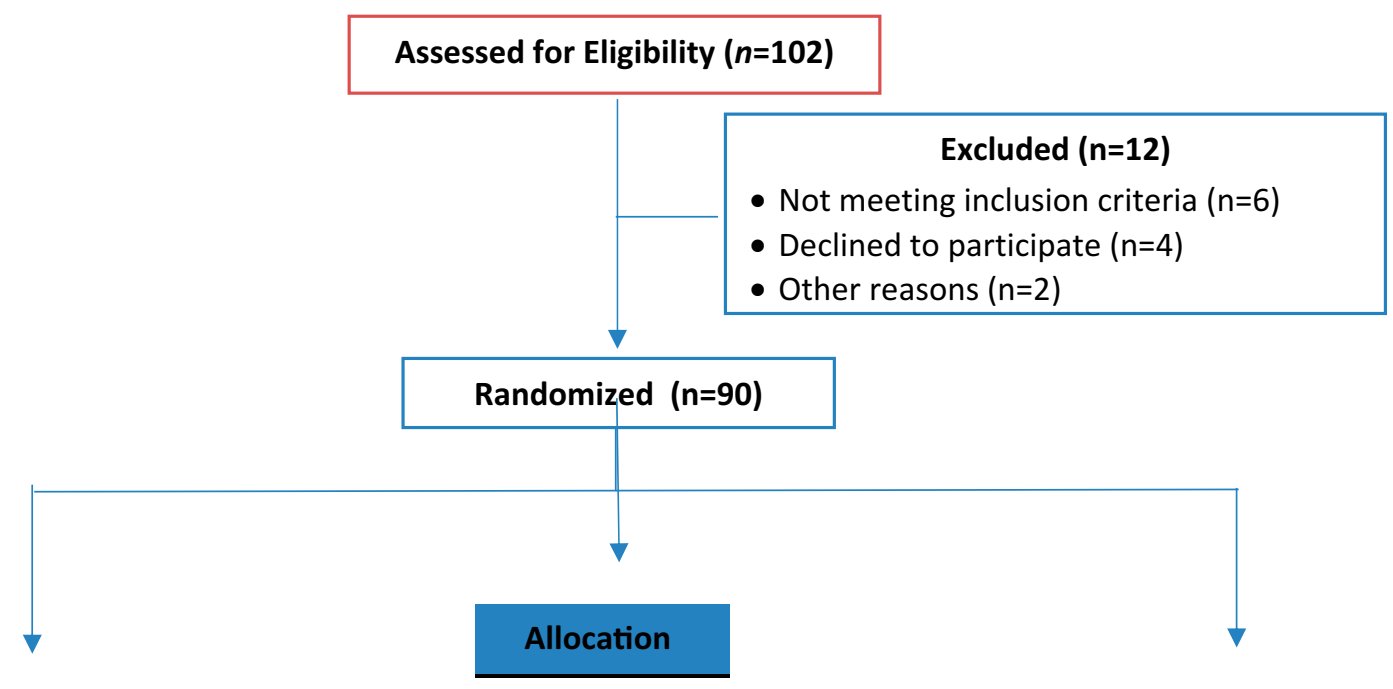

\section{Allocated to C group ( $n=30$ )}

- Received allocated intervention $(n=30)$.

- Did not receive allocated intervention $(n=0)$

\section{Allocated to $\mathbf{N}$ group $(\mathrm{n}=\mathbf{3 0})$}

- Received allocated intervention $(n=30)$.

- Did not receive allocated intervention $(n=0)$

\section{Allocated to M group ( $n=30)$}

- Received allocated intervention $(n=30)$.

- Did not receive allocated intervention $(n=0)$

\section{Follow-up}

\begin{tabular}{c}
\hline Lost to follow-up $(n=0)$ \\
Discontinued intervention $(n=0)$ \\
\hline
\end{tabular}

\begin{tabular}{c}
\hline Lost to follow-up $(n=0)$ \\
Discontinued intervention $(n=0)$ \\
\hline
\end{tabular}

Lost to follow-up $(n=0)$

Discontinued intervention $(n=0)$

\section{Analysis}

\section{Analyzed $(n=30)$}

Excluded from analysis $(n=0)$

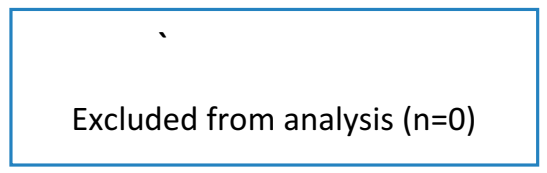

\section{Analyzed $(n=30)$}

Excluded from analysis ( $n=0)$

Figure I Consort diagram of the study.

randomization, patients were randomly assigned, by sealed envelope method, to one of three groups of 30 patients each:

Control Group (Group C): received $12.5 \mathrm{mg}$ hyperbaric bupivacaine $0.5 \%+0.5 \mathrm{~mL} 0.9 \%$ normal saline.

Nalbuphine Group (Group N): received $12.5 \mathrm{mg}$ hyperbaric bupivacaine $0.5 \%+1 \mathrm{mg}$ nalbuphine add in $0.5 \mathrm{~mL}$
$0.9 \%$ normal saline (Nalufin Amoun PharmaceuticalEgypt $20 \mathrm{mg} / \mathrm{mL}$ ).

Midazolam Group (Group M): received 12.5 mg hyperbaric bupivacaine $0.5 \%+2.5 \mathrm{mg}$ midazolam (equal $0.5 \mathrm{~mL}$ as the ampule of midazolam is $5 \mathrm{mg}$ in $1 \mathrm{~mL}$ ) (Midazolam hameln Sunny pharmaceutical-Egypt $5 \mathrm{mg}$ / $\mathrm{mL}$ solution). 
Patients and the anesthesiologist (the outcomes assessor) who recorded the perioperative data, were blinded to the study drugs.

In the sitting position and under complete aseptic precaution the subarachnoid block was performed at L3-L4 interspace or L4-L5 using 25 gauge Quincke spinal needle after local skin infiltration with lidocaine $2 \%$. After intrathecal injection patient laid in supine with pillow under the head and wedge under the right hip to maintain left uterine displacement. Oxygen (4 liter/minute) was administered via nasal cannula.

The primary outcomes were the effective analgesic time, and analgesic requirement postoperatively. Secondary outcomes were the characteristics of sensory and motor block (onset and duration), the adverse effects, sedation score, and Apgar score.

The onset and 2 segment regression of sensory block were recorded. The onset of sensory block is known as the time from end of intrathecal injection to absence of pain at T5 dermatome. It was tested by pinprick sensation using sterile needle in midclavicular line. Whereas the time for 2 segment regression of sensory block was defined as the time from end of intrathecal injection to 2 segment regression. It was evaluated every 15 minutes until 2 segment regression.

The onset and duration of motor block were also recorded and tested by Bromage score: ${ }^{13} \mathrm{I}=$ free movement of legs and feet; II = just able to flex knee with free movement of feet; III = unable to flex knee, but with free movement of feet; IV = unable to move legs or feet. The onset time of motor block was defined as the time from end of intrathecal injection to bromage score III. The duration of motor block was defined as the time from the onset of motor block to bromage score I. The duration of motor block was evaluated every 15 minutes until bromage score I.

Postoperative pain was evaluated at 1, 2, 3, 4, 6, 8, 10, $12,16,20,24$ hours postoperatively using the Numeric Pain Rating Scale (NPRS), which is a horizontal line $10 \mathrm{~cm}(0=$ no pain, $10=$ worst pain imaginable $)$. The mean NPRS in the first 24 hours postoperatively was recorded and the effective analgesic time was the time from intrathecal injection to NPRS $>3$. Ketorolac $30 \mathrm{mg}$ IV was administered when NPRS $>3$ or if requested by the patient, if NPRS was still $>3$ for 30 minutes after ketorolac, pethidine $0.5 \mathrm{mg} / \mathrm{kg}$ IV was given and the total analgesic doses were recorded.
The incidence of nausea, vomiting and shivering were recorded. Sedation was evaluated by sedation score: ${ }^{9} 1=$ awake and alert; 2 = sedated, responds to verbal stimulus; 3 $=$ sedated, responds to a mild physical stimulus; $4=$ sedated, responds to a moderate or strong physical stimulus; $5=$ not arousable. It was assessed at 30,60, 90, 120 minutes after intrathecal injection and the mean sedation score in this two hours was recorded, while Neonatal Apgar score ${ }^{14}$ was calculated by pediatrician at 1 and 5 minutes.

\section{Sample Size}

The sample size was calculated using Open Epi Info according to the following; the duration of sensory block of nalbuphine group was $205.14 \pm 5 \mathrm{~min}^{7}$ and in midazolam group was $190.8 \pm 39 \mathrm{~min}^{10}$ so at power of study $80 \%$ and C.I $95 \%$ and cases of control ratio 2:1, the sample was calculated to be 90 cases, 30 in each group.

\section{Statistical Analysis}

All data were collected, tabulated, and statistically analyzed using SPSS 20.0 for windows (SPSS Inc., Chicago, IL, USA 2011). Quantitative data were expressed as the mean \pm SD and qualitative data were expressed as absolute frequencies (number) and relative frequencies (percentage). F-test (ANOVA) was used to compare between more than two groups of normally distributed variables. Post hoc test was done to detect exactly which groups had a difference in means. Percent of categorical variables was compared using Chi-squared test. All tests were two sided. p-value $<0.05$ was considered statistically significant (S), p-value $<0.001$ was considered highly statistically significant (HS), and $p$-value $\geq 0.05$ was considered statistically insignificant (NS).

\section{Results}

The three groups were comparable regarding the demographic data (age, weight, height), and the duration of surgery $\mathrm{p}>0.05$ (Table 1 ).

Characteristics of the block (sensory and motor) were summarized in Table 2. The onset of sensory block was significantly rapid in group $\mathrm{N}(1.95 \pm 0.44 \mathrm{~min})$ compared to group $\mathrm{M}(2.23 \pm 0.50 \mathrm{~min})(\mathrm{p} 0.02)$ and group $\mathrm{M}$ was significantly rapid compared to group $\mathrm{C}(3.04 \pm 1.05 \mathrm{~min})$ $\mathrm{p}<0.001$. The 2 segment regression time of sensory block was $211.6 \pm 13.2 \mathrm{~min}$ in group $\mathrm{N}, 195.42 \pm 18.4$ $\mathrm{min}$ in group $\mathrm{M}$, and $162.3 \pm 11.8 \mathrm{~min}$ in group $\mathrm{C}$. The difference was statistically significant $(p<0.001)$ in the three groups with the highest duration in group $\mathrm{N}$ and lowest in group C. It was statistically significant between 
Table I Demographic Data and Duration of Surgery in Studied Groups

\begin{tabular}{|c|c|c|c|c|c|}
\hline Parameter & Group $C_{n}=30$ & Group N n = $\mathbf{3 0}$ & Group $M n=30$ & $\mathbf{F}$ & $\mathbf{P}$ \\
\hline Age (years) & $25.54 \pm 4.35$ & $25.43 \pm 3.66$ & $27.04 \pm 4.33$ & 1.42 & 0.24 \\
\hline Weight (kg) & $64.92 \pm 7.54$ & $63.7 \pm 5.72$ & $64.85 \pm 6.63$ & 0.31 & 0.73 \\
\hline Height (cm) & $158.78 \pm 3.98$ & $|58.98 \pm 4.4|$ & $160.01 \pm 4.35$ & 0.72 & 0.48 \\
\hline Duration of surgery (min) & $49.21 \pm 11.67$ & $47.43 \pm 13.53$ & $50.36 \pm|2.9|$ & 0.40 & 0.66 \\
\hline
\end{tabular}

Notes: Data were expressed as mean \pm SD; group C, control group; group N, nalbuphine group; group M, midazolam group; F-test (ANOVA), one way analysis of variance.

Table 2 Characteristics of the Block (Sensory and Motor) in Studied Groups

\begin{tabular}{|c|c|c|c|c|c|c|c|c|}
\hline Parameter & $\begin{array}{l}\text { Group C } \\
n=30\end{array}$ & $\begin{array}{l}\text { Group N } \\
\mathbf{n}=\mathbf{3 0}\end{array}$ & $\begin{array}{l}\text { Group } M \\
n=30\end{array}$ & $\mathbf{F}$ & $\mathbf{P}$ & $\begin{array}{l}\text { C\&N } \\
\text { PI }\end{array}$ & $\begin{array}{l}\text { C\&M } \\
\text { P2 }\end{array}$ & $\begin{array}{l}\text { N\&M } \\
\text { P3 }\end{array}$ \\
\hline Onset of sensory block (min.) & $3.04 \pm 1.05$ & $1.95 \pm .44$ & $2.23 \pm 0.50$ & 18.65 & 0.000 & $<0.001$ & $<0.001$ & 0.02 \\
\hline Onset of motor block (min.) & $4.88 \pm 0.65$ & $3.50 \pm 0.43$ & $4.03 \pm 0.80$ & 34.97 & 0.000 & $<0.001$ & $<0.001$ & 0.002 \\
\hline 2 segment regression time of sensory block ( $\mathrm{min}$.) & $162.3 \pm 11.8$ & $211.6 \pm 13.2$ & $195.42 \pm 18.4$ & 87.17 & 0.000 & $<0.001$ & $<0.001$ & $<0.001$ \\
\hline Duration of motor block (min.) & $146.43 \pm 28.7$ & $219.8 \pm 20.2$ & $197.1 \pm 26.7$ & 65.3 & 0.000 & $<0.001$ & $<0.001$ & $<0.001$ \\
\hline
\end{tabular}

Notes: Data were expressed as mean \pm SD; group C, control group; group N, nalbuphine group; group M, midazolam group; min, minute; pl, group C versus group N; 2 , group $C$ versus group $M ; p 3$, group $N$ versus group $M ; p<0.05$ was significant and $p<0.001$ was highly significant. F-test (ANOVA), one way analysis of variance. Post hoc test was done to detect exactly which groups had a difference in means.

groups $(\mathrm{C}, \mathrm{N}),(\mathrm{C}, \mathrm{M})$ and between $(\mathrm{N}, \mathrm{M}) \mathrm{p}<0.001$. The time of onset of motor block to bromage III was less in group $\mathrm{N}(3.50 \pm 0.43 \mathrm{~min})$ compared to group $\mathrm{M}(4.03$ $\pm 0.80 \mathrm{~min})$ with significant $\mathrm{p}$ value 0.002 . While it was less in group $\mathrm{M}(4.03 \pm 0.80 \mathrm{~min})$ compared to group C $(4.88 \pm 0.65 \mathrm{~min})(\mathrm{P}<0.001)$. The duration of motor block (the time of regression to bromage I) was $219.8 \pm$ $20.2 \mathrm{~min}$ in group $\mathrm{N}, 197.1 \pm 26.7 \mathrm{~min}$ in group $\mathrm{M}$, and $146.43 \pm 28.7 \mathrm{~min}$ in group C. It was more prolonged in group $\mathrm{N}$ and least in group $\mathrm{C}$. It was statistically significant different between groups $(\mathrm{C}, \mathrm{N}),(\mathrm{C}, \mathrm{M})$ and between $(\mathrm{N}, \mathrm{M}) \mathrm{p}<0.001$.

The mean NPRS in the first 24 hours postoperatively was higher in group C $(5.61 \pm 1.58)$ compared to group $\mathrm{N}(1.78$ $\pm 0.76)$ and group $\mathrm{M}(2.64 \pm 0.8) \mathrm{p}<0.001$. It was statistically significantly higher in group $\mathrm{M}$ than $\mathrm{N} \mathrm{p}<0.001$. The effective analgesic time showed significant prolongation in nalbuphine group (group N) $(263.7 \pm 16.3 \mathrm{~min})$ compared to group $\mathrm{M}(224.2 \pm 18.6 \mathrm{~min})$ and group $\mathrm{C}(185.5 \pm 17.45 \mathrm{~min})$ $(\mathrm{p}<0.001)$. With statistically significant prolongation in group $\mathrm{M}$ compared to group $\mathrm{C}(\mathrm{p}<0.001)$. The total analgesic doses of ketorolac and pethidine administered in the first 24 hours were highly statistically increased in group C compared to groups $\mathrm{N}$ and $\mathrm{M}(\mathrm{p}<0.001)$, with no significant difference between group $\mathrm{N}$ and group $\mathrm{M}$ in total pethidine dose p 0.3 (Table 3).

Regarding the recorded adverse effects; there was no significant difference between groups: 3 patients had hypotension in group $\mathrm{N}$ compared to 5 patients each in group $\mathrm{C}$ and $\mathrm{M}$. There was lowest incidence of vomiting, nausea and shivering in midazolam group, $p>0.05$, with no statistically significant difference. Patients in group $\mathrm{N}$ and group $\mathrm{M}$ showed statistically significantly more sedation $(1.78 \pm 0.63,2.75$ $\pm 0.54)$, respectively, compared to group $\mathrm{C}(0.61 \pm 0.12)$

Table 3 NPRS, The Effective Analgesic Time and Postoperative Analgesia of Studied Groups

\begin{tabular}{|c|c|c|c|c|c|c|c|c|}
\hline Parameter & $\begin{array}{l}\text { Group C } \\
n=30\end{array}$ & $\begin{array}{l}\text { Group N } \\
n=30\end{array}$ & $\begin{array}{l}\text { Group } M \\
n=30\end{array}$ & $\mathbf{F}$ & $\mathbf{P}$ & $\begin{array}{l}\text { C\&N } \\
\text { PI }\end{array}$ & $\begin{array}{l}\text { C\&M } \\
\text { P2 }\end{array}$ & N\&M P3 \\
\hline NPRS & $5.61 \pm 1.58$ & $1.78 \pm 0.76$ & $2.64 \pm 0.8$ & 97.86 & 0.000 & $<0.001$ & $<0.001$ & $<0.001$ \\
\hline Effective analgesic time (min) & $185.5 \pm 17.45$ & $263.7 \pm 16.3$ & $224.2 \pm 18.6$ & 150.19 & 0.000 & $<0.001$ & $<0.001$ & $<0.001$ \\
\hline Total ketorolac dose $(\mathrm{mg})$ in first 24 hours & $58.8 \pm 12.4$ & $37.9 \pm 15.2$ & $48.3 \pm 15.6$ & 15.65 & 0.000 & $<0.001$ & 0.005 & 0.01 \\
\hline $\begin{array}{l}\text { Total dose of pethidine } \\
(\mathrm{mg}) \text { in first } 24 \text { hours }\end{array}$ & $46.5 \pm 13.3$ & $31.6 \pm 10.8$ & $34.75 \pm 12.5$ & 12.34 & 0.000 & $<0.001$ & 0.001 & 0.3 \\
\hline
\end{tabular}

Notes: Data were expressed as mean \pm SD; group C, control group; group N, nalbuphine group; group M, midazolam group; min, minute; pl, group C versus group N; 2 , group C versus group M; 3 , group N versus group M; NPRS, Numeric Pain Rating Scale; $p<0.05$ was significant and $p<0.00$ I was highly significant. F-test (ANOVA), one way analysis of variance. Post hoc test was done to detect exactly which groups had a difference in means. 
$(\mathrm{p}<0.001)$. The Apgar score was lowest in group M $(6.9 \pm 0.73)$ compared to group C $(7.7 \pm 0.84)$ and group $\mathrm{N}(7.1 \pm 0.91)$, with statistically significant difference $(\mathrm{p}<0.001)$ at one minute without any danger to the baby, and no statistically significant difference between groups at 5 minutes (p 0.16) (Table 4).

\section{Discussion}

Effective intra- and postoperative analgesia is the principle goal of the anesthetist for smooth postoperative recovery. Spinal anesthesia is safe, economical, and easily administered with relatively short duration of local anesthetics. Adding adjuvant to local anesthetics decreases the doses of both drugs with reduction in associated adverse effects of each one. Therefore, the addition of intrathecal adjuvants is the most employed method to offer pain relief and prolong postoperative analgesia. ${ }^{6,15,16}$

Nalbuphine provides a significantly rapid onset of pain relief, probably because of its lipophilic properties. The present study showed that there was significantly rapid onset of sensory and motor block with slower regression of sensory block and time to bromage I in group $\mathrm{N}$ compared to groups M, C. Das et $\mathrm{al}^{7}$ compared the effect of different doses of nalbuphine with intrathecal anesthesia on the duration of postoperative analgesia. Also, Shakooh and Bhosle ${ }^{1}$ studied the effect of adding nalbuphine intrathecally with bupivacaine on the quality and duration of analgesia, their results showed significantly rapid onset of sensory and motor block with slower regression of the block when adding nalbuphine intrathecally. This was in agreement with the present study.

Conversely, Tiwari et $\mathrm{al}^{17}$ showed that the onset of motor and sensory block was not affected by the addition of intrathecal nalbuphine. This was attributed to lower dose of nalbuphine as they used $0.2 \mathrm{mg}$ and $0.4 \mathrm{mg}$ nalbuphine.
Regarding the effective analgesic time in the present study, it was prolonged in nalbuphine group compared to the control and midazolam groups with significant difference between groups. NPRS was significantly lower in group $\mathrm{N}$ compared to group $\mathrm{M}$ and group $\mathrm{C}$. Indeed, the total analgesic dose in the first 24 hours was least in nalbuphine group and highest in control group. There are some studies that are in agreement; Naaz et $\mathrm{al}^{4}$ studied the analgesic effect of intrathecal nalbuphine and fentanyl as adjuvant in lower limb orthopedic surgery. They found that the VAS score and the analgesic requirement in 24 hours were least in nalbuphine group. Gomaa et $\mathrm{al}^{18}$ compared intrathecal nalbuphine versus fentanyl for postoperative analgesia in cesarean section, their results showed that the duration of postoperative analgesia was prolonged with nalbuphine group. Similar results were demonstrated with the studies done by Brindra et al, ${ }^{5}$ Mukherjee et al, ${ }^{19}$ and Gupta et al. ${ }^{20}$

Intrathecal midazolam decreases the excitatory y -aminobutyric acid - mediated neurotransmission in the interneuron. This reduces the spinal dorsal horn neuron excitability. Indeed, midazolam causes release of endogenous opioid which acts on the spinal delta receptor. Thus, intrathecal midazolam improves intraoperative anesthesia and potentiates postoperative analgesia. ${ }^{21-24}$

The midazolam group in the present study showed rapid onset of sensory and motor blockade in contrast to control group with slower onset versus the nalbuphine group, these results are in agreement with Dodawad et al ${ }^{10}$ who added $2 \mathrm{mg}$ midazolam as an adjuvant intrathecally with bupivacaine for elective cesarean section in patients with pregnancy induced hypertension.

The duration of motor block of midazolam group in the present study was longer in contrast to control group, this

Table 4 Incidence of Adverse Effects, Sedation Score, and Apgar Score in Studied Groups

\begin{tabular}{|c|c|c|c|c|c|c|}
\hline \multicolumn{2}{|l|}{ Parameter } & $\begin{array}{l}\text { Group C } \\
n=30\end{array}$ & $\begin{array}{l}\text { Group } N \\
n=30\end{array}$ & $\begin{array}{l}\text { Group } M \\
\mathbf{n}=\mathbf{3 0}\end{array}$ & $x^{2}$ & $\mathbf{P}$ \\
\hline \multicolumn{2}{|l|}{ Hypotension } & 5 (16.66\%) & $3(10 \%)$ & 5 (16.66\%) & 0.719 & 0.69 \\
\hline \multicolumn{2}{|l|}{ Vomiting } & $4(13.33 \%)$ & $3(10 \%)$ & I (3.33\%) & 1.92 & 0.38 \\
\hline \multicolumn{2}{|l|}{ Nausea } & $2(6.66 \%)$ & I (3.33\%) & $0(0 \%)$ & 2.07 & 0.35 \\
\hline \multicolumn{2}{|l|}{ Shivering } & $3(10 \%)$ & I (3.33\%) & $0(0 \%)$ & 3.66 & 0.16 \\
\hline \multicolumn{2}{|c|}{ Sedation score } & $0.6 I \pm 0.32$ & $1.78 \pm 0.76$ & $2.75 \pm 0.54$ & (F) 106.36 & $<0.001$ \\
\hline \multirow[t]{2}{*}{ Apgar Score } & (I) $\min$ & $7.7 \pm 0.84$ & $7.1 \pm 0.91$ & $6.9 \pm 0.73$ & (F) 7.54 & $<0.001$ \\
\hline & (5) $\min$ & $9.4 \pm 1.7$ & $9.2 \pm 1.8$ & $8.7 \pm 0.43$ & (F) 1.85 & 0.16 \\
\hline
\end{tabular}

Notes: Data were expressed as No (\%), mean \pm SD; group C, control group; group N, nalbuphine group; group M, midazolam group; F-test (ANOVA), one way analysis of variance; $X^{2}$, chi-squared test; $p<0.05$ was significant and $p<0.001$ was highly significant. 
finding was consistent with Bharti et $\mathrm{al}^{25}$ study who showed prolonged duration of motor block in their midazolam group. In contrast Dodawad et al, ${ }^{10}$ their finding showed comparable duration of motor block in both control and midazolam groups. This was explained by the lower dose of bupivacaine $10 \mathrm{mg}$ and midazolam $2 \mathrm{mg}$ compared to the present study $12.5 \mathrm{mg}$ bupivacaine and $2.5 \mathrm{mg}$ midazolam. However they were in alignment with our study that there was significant longer effective analgesic time in midazolam group in contrast to the control group. A similar finding was also reported by other studies. ${ }^{26-28}$

Patients who received nalbuphine or midazolam with intrathecal bupivacaine were calm and sedated. Sedation score in the present study was comparable between nalbuphine and midazolam groups, but it was significantly higher compared to control group. These results are in accordance with Culebras et al, ${ }^{9}$ who compared nalbuphine versus morphine as an adjuvant to intrathecal bupivacaine in cesarean section. Similar results were shown by Dodawad et al. ${ }^{10}$ However, Shakooh and Bhosle's ${ }^{1}$ study did not agree, this disparity could be due to oldest age in their study (up to 65 years old).

In the present study, Apgar score was significantly lower in midazolam group at one minute and comparable in all groups at 5 minutes which is in accordance with the finding of Dodawad et al's ${ }^{10}$ study. There was less incidence of nausea, vomiting and shivering in midazolam group as benzodiazepine has action on chemoreceptor trigger zone with antiemetic effect ${ }^{29}$ with unclear mechanism for reducing shivering. ${ }^{10}$

\section{Limitation and Recommendation}

First; the variation between patients in pain threshold. Second; this study was limited to female patients undergoing elective cesarean section without comorbidities. Further studies are needed to know the effect of studied drugs on comorbidities such as diabetes or hypertension.

\section{Conclusion}

Adding $1 \mathrm{mg}$ nalbuphine to $12.5 \mathrm{mg}$ hyperbaric bupivacaine provided more effective postoperative analgesia than adding $2.5 \mathrm{mg}$ midazolam with less non-significant adverse effects in midazolam group in patients undergoing elective cesarean section.

\section{Data Sharing Statement}

The authors do not intend to share individual deidentified participant data.

\section{Disclosure}

This research did not receive any specific grant from funding agencies in the public, commercial, or not-forprofit sectors. The authors report no conflicts of interest in this work.

\section{References}

1. Shakooh S, Bhosle P. Intrathecal nalbuphine: an effective adjuvant for postoperative analgesia. Innov J Med Health Sci. 2014;4(2):79-82.

2. Shukla D, Verma A, Agarwat A, et al. Comparative study of intrathecal dexmedetomidine with intrathecal magnesium sulfate used as adjuvants to bupivacaine. J Anaesthesiol Clin Pharmacol. 2011;27 (4):495-499. doi:10.4103/0970-9185.86594

3. Ahmed FI. Intrathecal nalbuphine versus fentanyl as an adjuvant to bupivacaine in spinal anesthesia for elective cesarean section: a randomized double -blind study. Res Opin Anesth Intensive Care. 2019;6:112-118. doi:10.4103/roaic.roaic_109_17

4. Naaz S, Shukla U, Srivastava S, et al. A comparative study of analgesic effect of intrathecal nalbuphine and fentanyl as adjuvant in lower limb orthopedic surgery. J Clin Diagn Res. 2017;11(7):25-28.

5. Bindra TK, Kumar P, Jindal G. Postoperative analgesia with intrathecal nalbuphine versus intrathecal fentanyl in cesarean section: a double - blind comparative study. Anesth Essays Res. 2018;12 (2):561-565. doi:10.4103/aer.AER_41_18

6. Vishnuvardhan V, Hemalatha S, Shetty SM, et al. Effect of adding intrathecal magnesium sulphate to bupivacaine and fentanyl in lower abdominal and lower limb surgeries. J Dent Med Sci. 2016;15:44-48. doi:10.9790/0853-150754448

7. Das T, Ray H, Baliarsingh P. A comparative study of efficacy of intrathecal nalbuphine in different doses as an adjuvant to levobupivacaine in subarachnoid block. Sch J Appl Med Sci. 2017;5 (6E):2388-2392.

8. Rawal N, Nuutinen L, Raj PP, et al. Behavioral and histopathologic effects following intrathecal administration of butorphanol, sufentanil and nalbuphine in sheep. Anesthesiology. 1991;75:1025-1034. doi:10.1097/00000542-199112000-00015

9. Culebras X, Gaggero G, Jiri Z, et al. Advantages of intrathecal nalbuphine, compared with intrathecal morphine, after cesarean delivery: an evaluation of postoperative analgesia and adverse effects. Anesth Analg. 2000;91(3):601-605. doi:10.1213/00000539200009000-00019

10. Dodawad R, GB. S, Pandarpurkar S, et al. Intrathecal midazolam as an adjuvant in pregnancy induced hypertensive patients undergoing an elective caesarean section. A clinical comparative study. Anesth Pain Med. 2016;6(5):e 38550. doi:10.5812/aapm.38550

11. Kulkarni M, Kurdi M, Itagimath S, et al. The role of intrathecal midazolam as an adjuvant to bupivacaine in providing post-operative pain relief. Int J Health Allied Sci. 2012;1:231-234.

12. Child JD, Piva SR, Fritz M. Responsiveness of the numeric pain rating scale in patients with low back pain. Spine. 2005;30 (11):1331-1334. doi:10.1097/01.brs.0000164099.92112.29

13. Bromage PR. A comparison of the hydrochloride and carbon dioxide salts of lidocaine and prilocaine in epidural analgesia. Acta Anaesthesiol Scand Suppl. 1978;75:193-200.

14. Carlo WA. The newborn infant. In: Kliegman RM, Stanton BF, St. Geme JW, Schor NF, editors. Nelson Textbook of Pediatrics. 20th ed. Philadelphia, PA: Elsevier; 2016:chap 94.

15. Abdelhamid SA, El-lakany MH. Intrathecal dexmedetomidine: useful or not? Anesth Clin Res. 2013;4(9):351-356.

16. Gupta R, Verma R, Bogra J, et al. A comparative study of intrathecal dexmedetomidine and fentanyl as adjuvants to bupivacaine. J Anesthesiol Clin Pharmacol. 2011;27(3):339-343. doi:10.4103/ 0970-9185.83678 
17. Tiwari AK, Tomar GS, Agrawal J. Intrathecal bupivacaine in comparison with a combination of nalbuphine and bupivacaine for subarachnoid block: a randomized prospective double - blind clinical study. Am J Ther. 2013;20(6):592-595. doi:10.1097/ MJT.0b013e31822048db

18. Gomaa H, Mohamed NN, Zoheir HAH, et al. A comparison between postoperative analgesia after intrathecal nalbuphine with bupivacaine and intrathecal fentanyl with bupivacaine after cesarean section. Egypt J Anaesth. 2014;30:405-410. doi:10.1016/j.egja.2014.03.008

19. Mukherjee A, Pal A, Agarwal J, et al. Intrathecal nalbuphine as an adjuvant to subarachnoid block: what is the most effective dose ? Anesth Essays Res. 2011;5:171-175. doi:10.4103/0259-1162.94759

20. Gupta K, Rastogi B, Gupta PK, et al. Intrathecal nalbuphine versus intrathecal fentanyl as adjuvant to $0.5 \%$ hyperbaric bupivacaine for orthopedic surgery of lower limbs under subarachnoid block: a comparative evaluation. Indian J Pain. 2016;30:90-95. doi:10.4103/0970-5333.186463

21. Kohno T, Wakai A, Ataka T, et al. Action of midazolam on excitatory transmission in dorsal horn neurons of adult rat spinal cord. J Am Soc Anesthesiol. 2006;104:338-343. doi:10.1097/00000542-20060200000020

22. Good Child CS, Guo Z, Musgreave A, et al. Antinociception by intrathecal midazolam involves endogenous neurotransmitters acting at spinal cord delta opioid receptors. Br J Anaesth. 1996;77:758-763. doi:10.1093/bja/77.6.758
23. Gupta A, Kamat H, Kharod U. Efficacy of intrathecal midazolam in potentiating the analgesic effect of intrathecal fentanyl in patients undergoing lower limb surgery. Anesth Essays Res. 2015;9:379-383. doi:10.4103/0259-1162.164650

24. Mansour HS, Mohamad H. Effects of intrathecal midazolam in potentiating the analgesic effect of intrathecal dexmedetomidine in elderly patient undergoing hip repair surgeries. Res Opin Anesth Intensive Care. 2018;5:58-66.

25. Bharti N, Madan R, Mohanty PR, et al. Intrathecal midazolam added to bupivacaine improves the duration and quality of spinal anaesthesia. Acta Anaesthesiol Scand. 2003;47:1101-1105. doi:10.1034/j.1399-6576.2003.00186.x

26. Agrawal N, Usmami A, Sehgal R, et al. Effect of intrathecal midazolam bupivacaine combination on postoperative analgesia. Indian J Anaesth. 2005;49:37-39.

27. Kim MH, Lee YM. Intrathecal midazolam increases the analgesic effects of spinal blockade with bupivacaine in patients undergoing haemorrhoidectomy. Br J Anaesth. 2001;86(1):77-79. doi:10.1093/ bja/86.1.77

28. Sanwal MK, Baduni N, Jain A. Bupivacaine sparing effect of intrathecal midazolam in subarachnoid block for cesarean section. J Obstet Anaesth Crit Care. 2013;3(1):27-31. doi:10.4103/22494472.114288

29. Rodola F. Midazolam as an anti-emetic. Eur Rev Med Pharmacol Sci. 2006;10(3):121-126.
Journal of Pain Research

\section{Publish your work in this journal}

The Journal of Pain Research is an international, peer reviewed, open access, online journal that welcomes laboratory and clinical findings in the fields of pain research and the prevention and management of pain. Original research, reviews, symposium reports, hypothesis formation and commentaries are all considered for publication. The manuscript

\section{Dovepress}

management system is completely online and includes a very quick and fair peer-review system, which is all easy to use. Visit http:// www.dovepress.com/testimonials.php to read real quotes from published authors. 